\title{
Extended charge decomposition analysis and its application for the investigation of electronic relaxation
}

\author{
Serge I. Gorelsky · Edward I. Solomon
}

Published online: 18 April 2007

(C) Springer-Verlag 2007

\section{Erratum to: Theor Chem Acc}

\section{DOI 10.1007/s00214-007-0270-1}

Due to publisher's error that occurred at the stage of correction of the page proofs, the first sentence of the "Conclusion" is partly incorrect. It should read

"This study presents a molecular orbital method for the investigation of electronic structure contributions to the redox properties of different sites."

The online version of the original article can be found at http://dx.doi.org/10.1007/s00214-007-0270-1

S. I. Gorelsky · E. I. Solomon ( $\varangle)$

Department of Chemistry, Stanford University,

Stanford, CA 94305, USA

e-mail: Edward.Solomon@Stanford.edu

S. I. Gorelsky

Centre for Catalysis Research and Innovation,

Department of Chemistry, University of Ottawa,

Ottawa, ON, K1N 6N5, Canada

e-mail:sg@sg-chem.net 